\title{
Closed subtalar dislocation with non-displaced fractures of talus and navicular: a case report and review of the literature Elias Fotiadis ${ }^{1}{ }^{*}$, Christos Lyrtzis $^{1}$, Theodoros Svarnas ${ }^{1}$, Miltos Koimtzis ${ }^{1}$, Kiriaki Akritopoulou ${ }^{2}$ and Byron Chalidis ${ }^{3}$
}

\footnotetext{
Addresses: ${ }^{1}$ Orthopaedic Department, General Hospital of Veria, Veria, 59100, Greece

${ }^{2}$ Medical School, Aristotle University of Thessaloniki, Thessaloniki, 54124, Greece

${ }^{3}$ Orthopaedic Department, Avenue Hospital, Melbourne, Australia
}

Email: EF* - fotiad-e@otenet.gr; CL - lyrtzischristos@yahoo.gr; TS - nixterida@hotmail.com; MK - akritop@otenet.gr; KA - akritop@otenet.gr; BC - byronchalidis@gmail.com

* Corresponding author

Received: 28 July 2009 Accepted: 8 August 2009 Published: I September 2009

Cases Journal 2009, 2:8793 doi: 10.4076/1757-1626-2-8793

This article is available from: http://casesjournal.com/casesjournal/article/view/8793

(C) 2009 Fotiadis et al.; licensee Cases Network Ltd.

This is an Open Access article distributed under the terms of the Creative Commons Attribution License (http://creativecommons.org/licenses/by/3.0), which permits unrestricted use, distribution, and reproduction in any medium, provided the original work is properly cited.

\begin{abstract}
Closed subtalar dislocations associated with talus and navicular fractures are rare injuries. We report on a case of a 43-year-old builder man with medial subtalar dislocation that was further complicated by minimally displaced talar and navicular fractures. Successful closed reduction under general anesthesia was followed by non-weight bearing and ankle immobilization with a below-knee cast for 6 weeks. At 3 years post-injury, the subtalar joint was stable, the foot and ankle mobility was in normal limits and the patient could still work as a builder. However, he complained for occasionally mild pain due to the development of post-traumatic arthritis in subtalar and ankle joints. Our search in literature revealed that conservative treatment of all the successfully reduced and minimally displaced subtalar fracture-dislocations has given superior results compared to surgical management. However, even in cases with no or slight fracture displacement, avascular necrosis of the talus or arthritis of the surrounding joints can compromise the final functional outcome.
\end{abstract}

\section{Introduction}

Subtalar dislocation is a rare ankle injury. Although it can occur in any direction, medial dislocation is the most common injury pattern [1]. The lesion is usually closed [2] as a result of a high-energy injury such as fall from a height or motor vehicle accident [1]. Associated fractures may be easily overlooked and lead to disruption of the normal bone articulation, arthritis or avascular necrosis of the talus [3].
We report a case of closed subtalar dislocation with concomitant and ipsilateral talus and navicular fractures. At 3 years postoperatively, the foot scored well in terms of stability and range of motion but post-traumatic arthritis compromised the final result. We also present our results from the review of English literature regarding the incidence and the main characteristics of the injury, as well as the outcome of the applied treatment options. 
The Hospital's Scientific Research Board approved this study, which was conducted in accordance with the World Medical Association Declaration of Helsinki of 1975 as revised in 2000. The patient was informed about his participation in the study and gave informed consent.

\section{Case presentation}

A 43-year-old Greek male builder admitted to the Accident and Emergency Department of the Hospital due to fall from a height of about $2.5 \mathrm{~m}$. The patient complained of severe right ankle pain and inability to bear any weight on his extremity. In clinical examination the ankle was substantially swollen and ecchymotic, while the talonavicular and medial subtalar joints were very tender and painful to palpation. However, no neurovascular or tendon disturbances were identified. Both oblique and anteroposterior radiographs showed medial displacement of the midfoot without any evidence of bone fracture. (Figures $1 \mathrm{a}$ and $\mathrm{b}$ ).

Under general anesthesia, the subtalar dislocation was successfully reduced with manual pressure on the head of the talus and traction, plantar flexion and pronation of the forefoot. The knee was kept flexed throughout the relocation process for eliminating the tension of the soleus muscle. Afterwards, the quality of the reduction and the stability of the subtalar joint were evaluated under fluoroscopy. As no signs of anteroposterior or mediolateral instability were recognized, the ankle was immobilized in a short leg non-weight-bearing cast for 6 weeks. A post-reduction compute tomography (CT) scan was also performed to confirm the anatomic reduction of the subtalar joint dislocation and reveal any potential fractures. The CT scan showed a nondisplaced fracture of the talus body, an osteochondral fracture of the head of the talus and a nondisplaced navicular fracture (Figure 2). Due to the benign character of all fractures, no surgical treatment was decided.

After cast removal, an intensive foot and ankle physiotherapy program was commenced for restoring the foot and ankle mobility and preventing stiffness. The patient was limited to partial weight bearing for another 2 weeks and after that time he progressed to weight bearing as tolerated.

At 3 year follow up examination, the patient performed well in terms of foot and ankle range of motion. No signs of instability were identified. The good clinical result was also illustrated from the AOFAS [4], ankle hind foot scale, as a total score of 90 out of 100 points was achieved. Although, the patient returned to his prior to injury occupation, he complained occasionally for mild pain. The latter was attributed to the development of sclerotic changes in the body of the talus and post-traumatic osteoarthritis in subtalar and ankle joints (Figure 3).
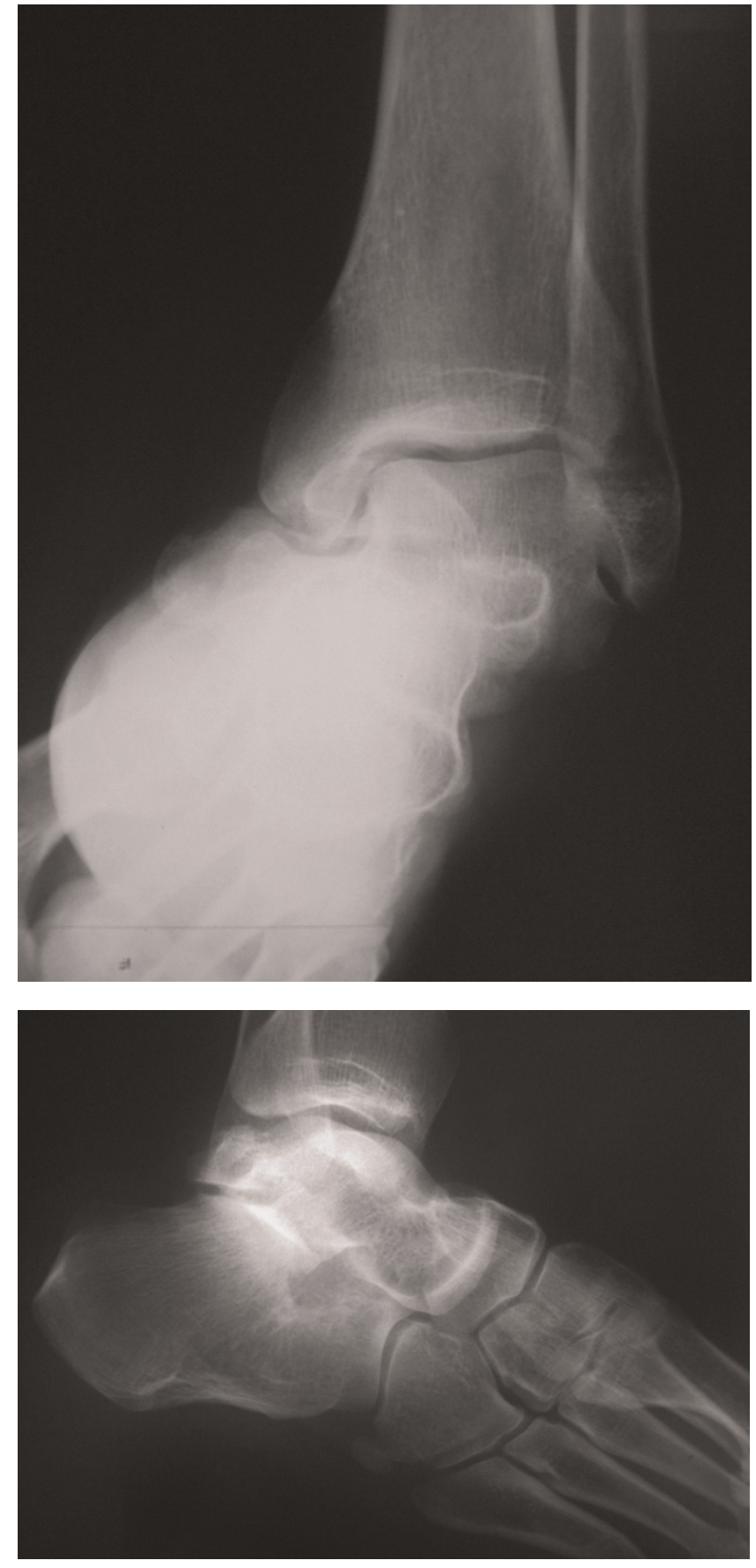

Figure I. Anteroposterior (a) and oblique (b) foot radiographs illustrate medial subtalar dislocation of the right foot.

\section{Discussion}

Closed subtalar dislocations may be associated with concomitant intra-articular fractures of the osseous elements of foot and ankle [2]. Combined injuries can prolong the immobilization period as well as the 


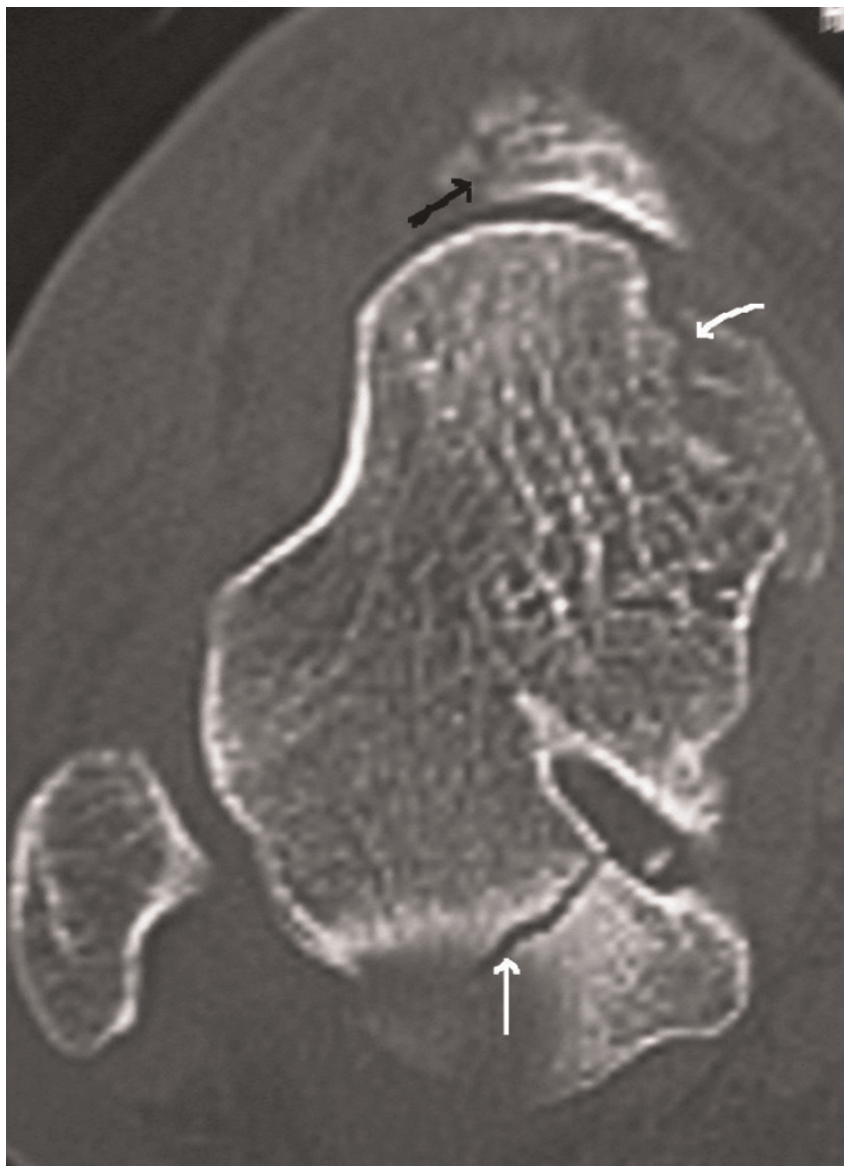

Figure 2. CT scan of the right foot showing two osteochondral fractures of the talus (white arrows) and an undisplaced navicular fracture (black arrow).

incidence and magnitude of complications, such as arthritis of the subtalar joint or avascular necrosis of the body of talus [3].

Our search in English literature revealed 26 published studies with 328 patients suffering from closed subtalar dislocations (Table 1$)$. In the majority of cases (86\%), the lesions were treated conservatively with a below-knee cast and non-weight bearing for at least 3-6 weeks. The described results were generally good to excellent despite some residual pain or stiffness in subtalar and ankle joints [5-9]. Heppenstall et al [10] reported excellent functional results in 14 out of 19 patients after closed reduction of subtalar dislocation. However, 16 of 20 patients had significant restriction of subtalar motion and 6 of 20 patients had roentgenographic evidence of arthritis, after an average of 4.2 years follow-up period. Jarde et al [11] noticed good to excellent results in 24 of 35 cases with the same injury type. At the same study, 3 patients developed talar necrosis in a mean period of 1 year.

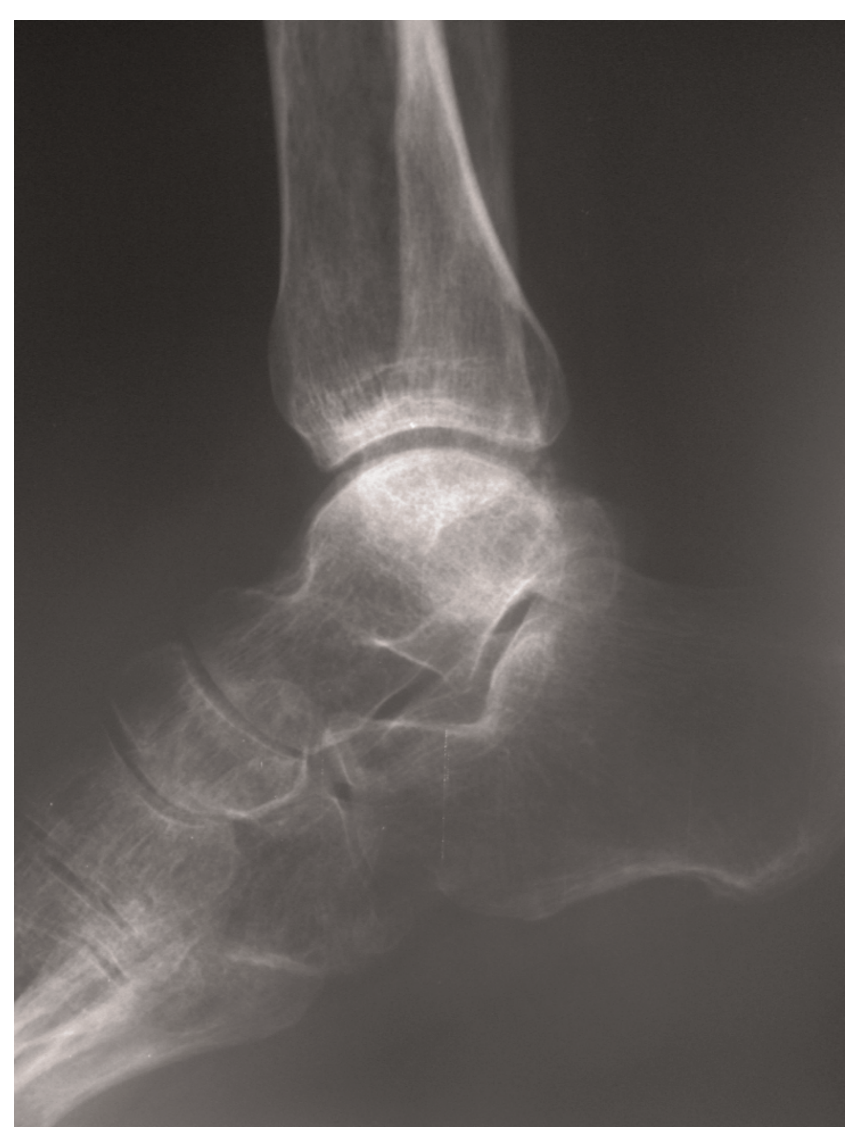

Figure 3 Lateral radiograph of the ankle 3 years post-injury. Sclerosis of the body of the talus and degenerative changes in ankle and subtalar joints are evident.

Pure dislocations seem to have a more favorable prognosis compared to combined injuries and associated fractures $[12,13]$. In addition, open reduction and surgical fixation of the lesion was largely related to a poor result [14]. Merchan [15], described less favorable results in almost half of the 23 patients with closed subtalar dislocation. Interestingly, 6 out of 23 patients that were treated with open reduction and K-wires fixation had fair or poor final outcome. On the other hand, Kanda et al [16] and Chuo et al [17] reported good results and only mild ankle soreness after open reduction of the dislocation. Finally, Ganel et al [18] and Love et al [19] found that conservative and surgical treatment of closed subtalar dislocations were equal in terms of ankle and foot function.

According to the published studies, there is no general agreement regarding the proper immobilization period after successful reduction of the subtalar dislocation. DeLee and Curtis [20], found that in isolated cases without concomitant fractures, 3 weeks of immobilization 


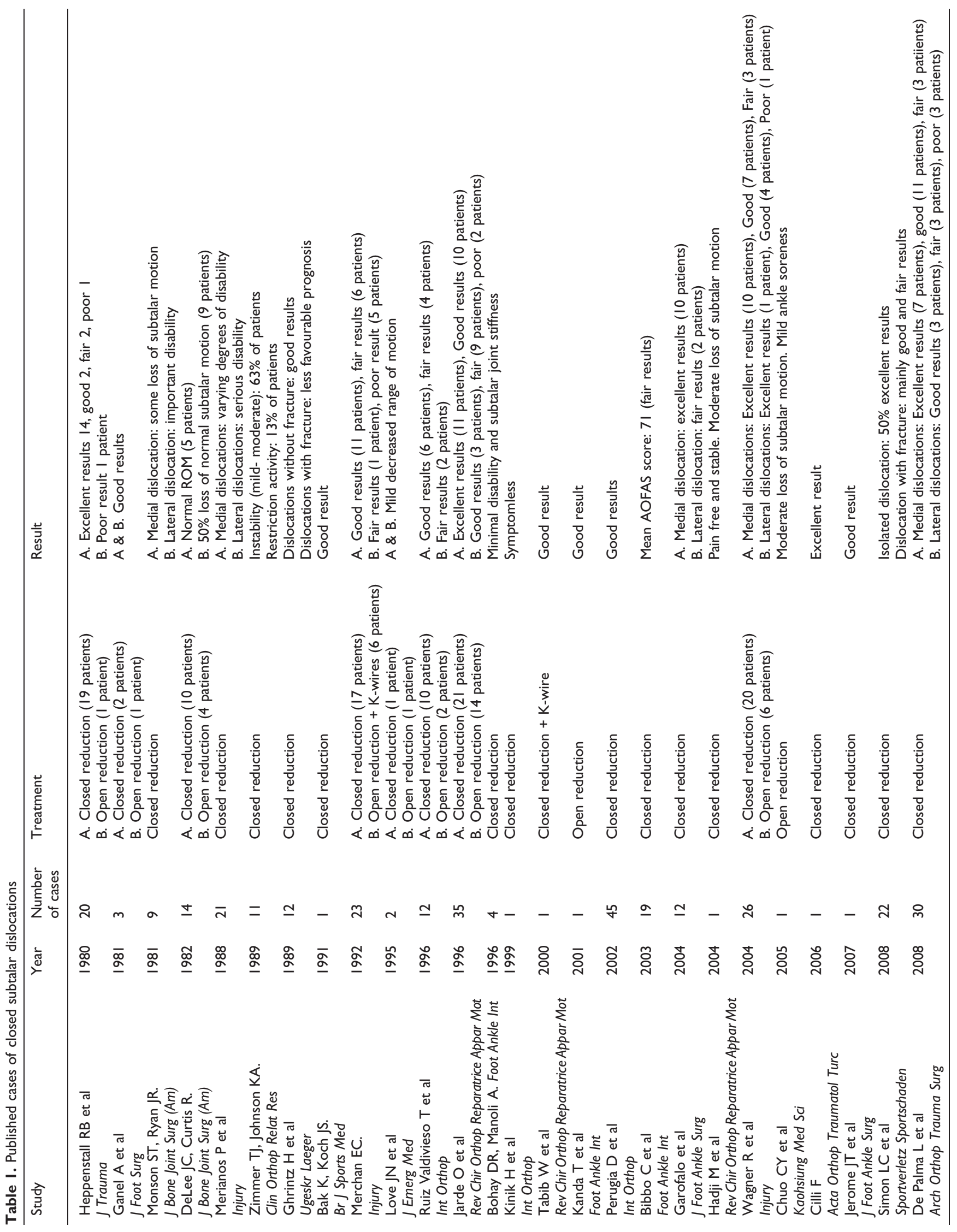


could offer adequate joint stability and almost normal ROM. On the contrary, there was a decrease of $50 \%$ in subtalar motion when a concomitant foot or ankle fracture existed and the immobilization period prolonged to more than 6 weeks. Similarly, Bohay and Manoli [21], stated that the factors resulting in a poor outcome after a subtalar dislocation were open lesions, bone fractures and prolonged immobilization. However, Zimmer and Johnson [22] advocated that subtalar instability (symptomatic) could occur in younger patients (average age 26 years) that treated with shorter periods of immobilization. Specifically, mild to moderate instability was developed in $62.5 \%$ of cases after a mean immobilization period of 4.4 weeks (range 3-9 weeks). Despite the diversity of the available clinical results, it seems that ankle immobilization should not be less than 6-8 weeks in case of associated undisplaced talus or navicular fractures [23].

The direction of dislocation seems to play also a significant role in the final functional outcome. Medial subtalar dislocations usually have shown good results when treated conservatively, while lateral dislocations have been associated with important disability [24-28]. However, Perugia et al [29] reported no significant difference in the AOFAS score between medial and lateral subtalar dislocations in a series of 45 patients. The authors pointed out that if pure low-energy subtalar dislocations were promptly reduced and immobilized for 4 weeks, a favorable outcome should be anticipated.

In the current case report, we emphasize that even careful scrutinize of the initial radiographs could not be always adequate for identifying any associated fractures. In this case, the clinical result may be complicated by stiffness and painful deformity. Therefore, we advocate further examination with CT scan after reduction of the dislocation. However, and despite the meticulous evaluation of the injured area, the current treatment methods cannot preclude the possibility of avascular necrosis of the talus and posttraumatic arthritis. These findings, which were also evident in our case, underline the severity of the injury and the magnitude of damage in both bone and soft tissue structures.

In conclusion, additional radiologic examination may be of clear benefit in all the subtalar dislocations. Conservative treatment remains the optimal treatment choice for the all the dislocation types without concomitant displaced fractures. However, the long-term performance of the foot is unpredictable due to the risks of avascular necrosis of the talus and degenerative arthritis.

\section{Consent}

Written informed consent was obtained from the patient for publication of this case report and accompanying images. A copy of the written consent is available for review by the journal's Editor-in-Chief.

\section{Competing interests}

The authors declare that they have no competing interests.

\section{Authors' contributions}

EF was a major contributor in writing the manuscript. BC was a major contributor in writing and in editing the manuscript. CL analyzed and interpreted the patient data regarding the injury. TS collected the bibliography of this injury. MK and KA were responsible for X-ray, CT examination and follow up of the patient.

\section{References}

I. Jerome JT, Varghese M, Sankaran B: Anteromedial Subtalar dislocation. J Foot Ankle Surg 2007, 46:52-54.

2. Bibbo C, Anderson RB, Davis WH: Injury characteristics and the clinical outcome of Subtalar dislocations: a clinical and radiographic analysis of $\mathbf{2 5}$ cases. Foot Ankle Int 2003, 24: I 58-I63.

3. Lancaster S, Horowitz M, Alonso J: Subtalar dislocations: a prognosticating classification. Orthopaedics I985, 8: I 234-I 240.

4. Kitaoka HB, Alexander IJ, Adelaar RS, Nunley JA, Myerson MS, Sanders $M$ : Clinical rating systems for the ankle-hindfoot, midfoot, hallux, lesser toes. Foot and Ankle Int 1994, 1 5:349-353.

5. Bak K, Koch JS: Subtalar dislocation in a handball player. $\mathrm{Br} J$ Sports Med 1991, 25:24-25.

6. Kinik H, Octay O, Arican M, Mergen E: Medial subtalar dislocation. Int Orthop 1999, 23:366-367.

7. Tabib W, Lemonne F, Aboufarah F, Nguyen Duy T, Asselineau A, Bombart $M$ : Anterior subtalar dislocation associated with a fracture of the calcaneus: a case report and review of the literature. Rev Chir Orthop Reparatrice Appar Mot 2000, 86: 197-203.

8. Hadji M, Golli M, Moalla R, Kmantar L, Hamdi A: Conservative treatment of talar dislocation: a case report. Rev Chir Orthop Reparatrice Appar Mot 2004, 90:285-288.

9. Cilli F: Limitation in subtalar motion in a patient nine years after treatment for medial subtalar dislocation. Acta Orthop Traumatol Turc 2006, 40:173-I75.

10. Heppenstall RB, Farahvar H, Balderston R, Lotke P: Evaluation and management of subtalar dislocations. J Trauma 1980, 20:494-497.

II. Jarde O, Trinquier-Lautard JL, Merti P, Tran Van F, Vives P: Subtalar dislocations. Apropos of $\mathbf{3 5}$ cases. Rev Chir Orthop Reparatrice Appar Mot 1996, 82:42-48.

12. Ghrintz H, Pahle E, Falster O: Subtalar luxation. Ugeskr Laeger 1989, I5 I:1674-1675.

13. Simon LC, Schulz AP, Faschingbaker M, Morlock M, Jurgens C: Basketball foot-long-time prognosis after peritalar dislocation. Sportverlatz Sportschaden 2008, 22:31-37.

14. Ruiz Valdivieso T, de Miquel Vielba JA, Hernandez Garcia C, Castillo AV, Alvarez Posadas JI, Sanchez Martin MM: Subtalar dislocations. A study of nineteen cases. Int Orthop 1996, 20:83-86.

15. Merchan EC: Subtalar dislocations: long-termfollow-up of 39 cases. Injury 1992, 23:97-100.

16. Kanda T, Sakai H, Koseki K, Tamai K, Takeyama N, Saotome K: Anterior dislocation of the subtalar joint: a case report. Foot Ankle Int 2001, 22:609-6II.

17. Chuo CY, Lu CC, Liu PC, Shen WJ: Anterior subtalar dislocation: a case report. Kaohsiung J Med Sci 2005, 21:40-43.

18. Ganel A, Ahronson Z, Heim M, Pritch M, Chechick A: Subtalar dislocations. J Foot Surg 1981, 20:|42-|44.

19. Love JN, Dhindsa HS, Hayden DK: Subtalar dislocation: evaluation and management in the emergency department. J Emerg Med 1995, I3:787-793.

20. Delee JC, Curtis R: Subtalar dislocation of the foot. J Bone Joint Surg $(A m)$ 1982, 64:433-437.

21. Bohay DR, Manoli A: Occult fractures following subtalar joint injuries. Foot Ankle Int 1996, I7:164-169. 
22. Zimmer TJ, Johnson KA: Subtalar dislocations. Clin Orthop Relat Res 1989, 238:190-194.

23. Andrew GM: Fractures and dislocation of foot. In Campbell's Operative Orthopedics. Volume I. I0th edition. Edited by Terry Canale. St Louis: Mosby; 2003:423I-4283.

24. Monson ST, Ryan JR: Subtalar dislocation. J Bone Joint Surg (Am) 198I, 63:II56-II58.

25. Merianos P, Papagiannakos K, Hatzis A, Tsafantakis E: Peritalar dislocation: a follow-up report of 21 cases. Injury 1988, 19:439-442.

26. Garofalo R, Moretti B, Ortolano V, Cariola P, Solarino G, Wettstein M, Mouhsine E: Peritalar dislocations: a retrospective study of 18 cases. J Foot Ankle Surg 2004, 43:166-172.

27. Wagner R, Blattert TR, Wechbach A: Talar dislocations. Injury 2004, 35:5B36-45.

28. de Palma L, Santucci A, Marinelli M, Borgogno E, Catalani A: Clinical outcome of closed isolated subtalar dislocations. Arch Orthop Trauma Surg 2008, 128:593-598.

29. Perugia D, Basile A, Massoni C, Gumina S, Rossi F, Ferretti A: Conservative treatment of subtalar dislocations. Int Orthop 2002, 26:56-60.

\section{Do you have a case to share?}

Submit your case report today

- Rapid peer review

- Fast publication

- PubMed indexing

- Inclusion in Cases Database

Any patient, any case, can teach us something

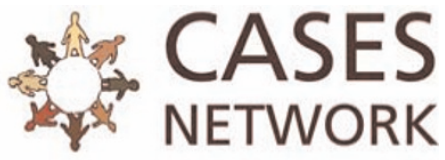

www.casesnetwork.com 